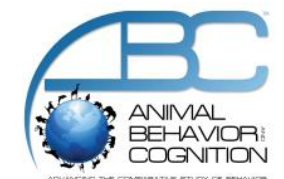

\title{
Diurnal and Nocturnal Activity Time Budgets of Asian Elephants (Elephas maximus) in a Zoological Park
}

\author{
Denise E. Lukacs ${ }^{1, *}$, Melanie Poulin ${ }^{1}$, Hayley Besenthal ${ }^{1}$, Otto C. Fad ${ }^{2}$, Stephen P. Miller ${ }^{1}$, \\ James L. Atkinson ${ }^{1}$, \& Esther J. Finegan ${ }^{1}$
}

\author{
${ }^{1}$ Department of Animal and Poultry Science, University of Guelph \\ ${ }^{2}$ Busch Gardens Tampa Bay \\ *Corresponding author (Email: dlukacs@ mail.uoguelph.ca)
}

Citation - Lukacs, D. E., Poulin, M., Besenthal, H., Fad, O. C., Miller, S. P., Atkinson, J. L., \& Finegan, E. J. (2016). Diurnal and nocturnal activity time budgets of Asian elephants (Elephas maximus) in a zoological park. Animal Behavior and Cognition, 3(2), 63-77. doi: 10.12966/abc.01.05.2016

\begin{abstract}
The diurnal and nocturnal activity time budgets of five adult female Asian elephants (Elephas maximus) were studied in a zoological park for two 24-hour, five 14-hour, and one 9-hour observation periods between May and June 2011. Relatively few studies have looked at detailed daytime and nighttime activity time budgets in captive Asian elephants. Continuous observation was used to measure the activity time budgets of at least one focal animal per observation period. The activity time budgets varied between animals and observation periods. The elephants spent $17-49 \%$ of the day (daylight hours) standing, 1-9\% of the day walking, 19-44\% of the day eating, and 1-20\% of the day using enrichment items. At night, the elephants spent $29-87 \%$ of the observation period standing, 1-19\% of the night eating, and $0.1-10 \%$ of the night using enrichment items. At night, elephants spent $0-45 \%$ of the observation period lying down. Variations in activity time budgets between elephants and observation periods have been observed in other studies of captive and wild elephants. Results of this observational study allow comparison between groups of captive elephants and between captive and wild elephants. Furthermore, results of this study can inform management strategies.
\end{abstract}

Keywords - Animal management, Asian elephant, Behavior, Elephas maximus, Husbandry, Thermoregulation, Welfare

The Asian elephant (Elephas maximus) is the second largest land mammal, and part of the megaherbivores, which are plant-eating land mammals weighing over $1000 \mathrm{~kg}$ at maturity (Owen-Smith, 1988). The Asian elephant is found in the wild in fragmented populations in south and southeast Asia (Choudhury et al., 2008), with an endangered population size of 41,410-52,345 (Choudhury et al., 2008). It is estimated that the population size has declined at least 50\% over the last three generations (60-75 years), due to habitat loss, habitat degradation and other threats such as poaching (Choudhury et al., 2008).

In captivity, up to 16,000 Asian elephants may be kept as work animals in Asia (Clubb \& Mason, 2002; Sukumar, 1992). Another 1800 Asian elephants may live in captivity, in zoological and safari parks, and as circus animals (Koehl, 2001). 


\section{Asian Elephants in the Wild}

Asian elephants in the wild live in a variety of habitats, including grassland, forest and scrubland (Choudhury, 1999). The size of home ranges can vary greatly; home ranges of 10 to 800 square kilometers have been described (Clubb \& Mason, 2002; Fernando et al., 2005). Asian elephants are generalists and browse and graze on a variety of plants. They will eat grasses, leaves, twigs, bark, and roots, and the plant types in the diet will depend on the habitat and season (McKay, 1973; Owen-Smith, 1988). A wide variety of plant species may be eaten. For example, wild Asian elephants in India have been seen to feed on 82 species of plants, including 59 woody plant and 23 grass species (Choudhury et al., 2008). More browse is eaten during the dry season. For example, grasses make up 55\% of the diet in the wet season and browse makes up $70 \%$ of the diet in the dry season, for the elephants in southern India (Sukumar, 1992). In another study of wild elephants in India, the diet is made up mostly of grass (84\%) except during the dry season when browse can form up to $47 \%$ of the diet (Choudhury et al., 2008).

Asian elephants will eat 1-1.9\% of their body mass per day in feed (Owen-Smith, 1988; Roehrs, Brockway, Ross, Reichard, \& Ullrey, 1989). In wild elephants, this equates to 150 to $350 \mathrm{~kg}$ wet weight of feed and 60-80\% of waking hours spent foraging and eating (Dougall, 1964; McKay, 1973; OwenSmith, 1988; Shoshani \& Eisenberg, 1982).

\section{Activity Time Budgets}

Few studies have looked at detailed activity time budgets of elephants. The studies that have looked at Asian elephant behavior have found considerable variation between individuals, habitats and seasons, in both wild and captive animals (e.g., Rees, 2009; Sukumar, 1992). Variations in behavior have also been seen due to differences in housing and management (e.g., Posta, 2011). Furthermore, some studies have used short sampling periods and thus a detailed activity time budget cannot be determined. For example, Tresz and Wright (2006) observed a group of Asian elephants in a zoological park for four $10 \mathrm{~min}$ sampling periods per day. In this study, $37.9 \%$ of the observation period was spent foraging, $13.2 \%$ of the time spent in locomotion, and $17.6 \%$ of the time spent standing. Stoinski, Daniel, and Maple (2000) collected data on a group of African elephants (Loxodonta africana) in a zoological park for 30 minutes twice a day, using scan sampling, and determined feeding occurred for $47-80 \%$ of the scans in the morning and 20.5-36.7\% in the afternoon, with longer feeding times seen when feeding enrichment was implemented. Locomotion was observed for 3.3-6.5\%, while inactivity occurred between 0.6-7.6\% of the scans. Wilson, Bloomsmith, and Maple (2004) and Wilson, Bashaw, Fountain, Kieschnick, and Maple (2006) used instantaneous focal sampling periods of one hour.

A recent study by Horback, Miller, Andrews, \& Kuczaj (2014) observed a mixed age and sex herd of 15 African elephants, and reported a difference between diurnal and nocturnal activity time budgets. Collectively these elephants engaged first in foraging, followed by resting during both day and night.

The objective of this study was to establish a detailed diurnal and nocturnal activity time budget for a group of Asian elephants in a zoological park, and to compare activity time budgets between elephants and between observation days, as well as to discuss differences noted compared to previous literature. A greater knowledge of elephant behavior can help inform management practices, and serve as a basis for comparative evaluations of other captive or wild elephants.

\section{Method}

\section{Study Animals and Husbandry}

This study was approved by the University of Guelph Animal Care committee and through the Sea World Parks and Entertainment, Inc. Zoological Research Review. Five adult female Asian elephants at Busch Gardens Tampa (Tampa, Florida, USA) were studied (Table 1). Dominance hierarchy was stable 
throughout the study and based on elephant trainer observations (Personal communication, O. Fad, D. Donahue, M. Gramling).

Table 1

Age, Weight, and Dominance Rank of Elephants at Time of Study

\begin{tabular}{cccc}
\hline Elephant & Age (years) & Weight (kg) & Dominance \\
\hline T & 44 & 3090 & 1 \\
S & 45 & 3450 & 2 \\
K & 22 & 3640 & 3 \\
R & 43 & 3730 & 4 \\
C & 41 & 3680 & 5 \\
\hline
\end{tabular}

Note. Elephant $\mathrm{K}$ is the offspring of Elephant $\mathrm{C}$.

The elephants reside primarily in an outdoor habitat (Figure 1), surrounded by a dry moat and gunite walls, with a sand substrate. The habitat has a drinker, a large swimming pool, and a sail shade structure. There are also areas of shade produced by trees and nearby structures at various times during the day. The elephants are brought into an elephant barn each morning (approximately 06:30-09:30 h) to allow cleaning of the outdoor habitat, as well as for approximately $45 \mathrm{~min}$ in the early afternoon to allow enrichment items to be placed outside. Unless the weather is especially inclement or cold, the elephants normally have no access to the indoor area when in the outdoor habitat. Elephants could associate freely with each other outside. The elephants have access to Western timothy hay at all times, and a concentrate feed is given in the morning in the barn. Produce (various vegetables and fruits) and browse are also given as enrichment. Other enrichment items include plastic toys (such as balls and boxes), tires, and wood logs. The type and location of enrichment items varies daily. In fact one key principle of the Busch Gardens Tampa elephant program is to avoid routines and thereby encourage social and behavioral flexibility by providing a dynamic environment for the elephants.

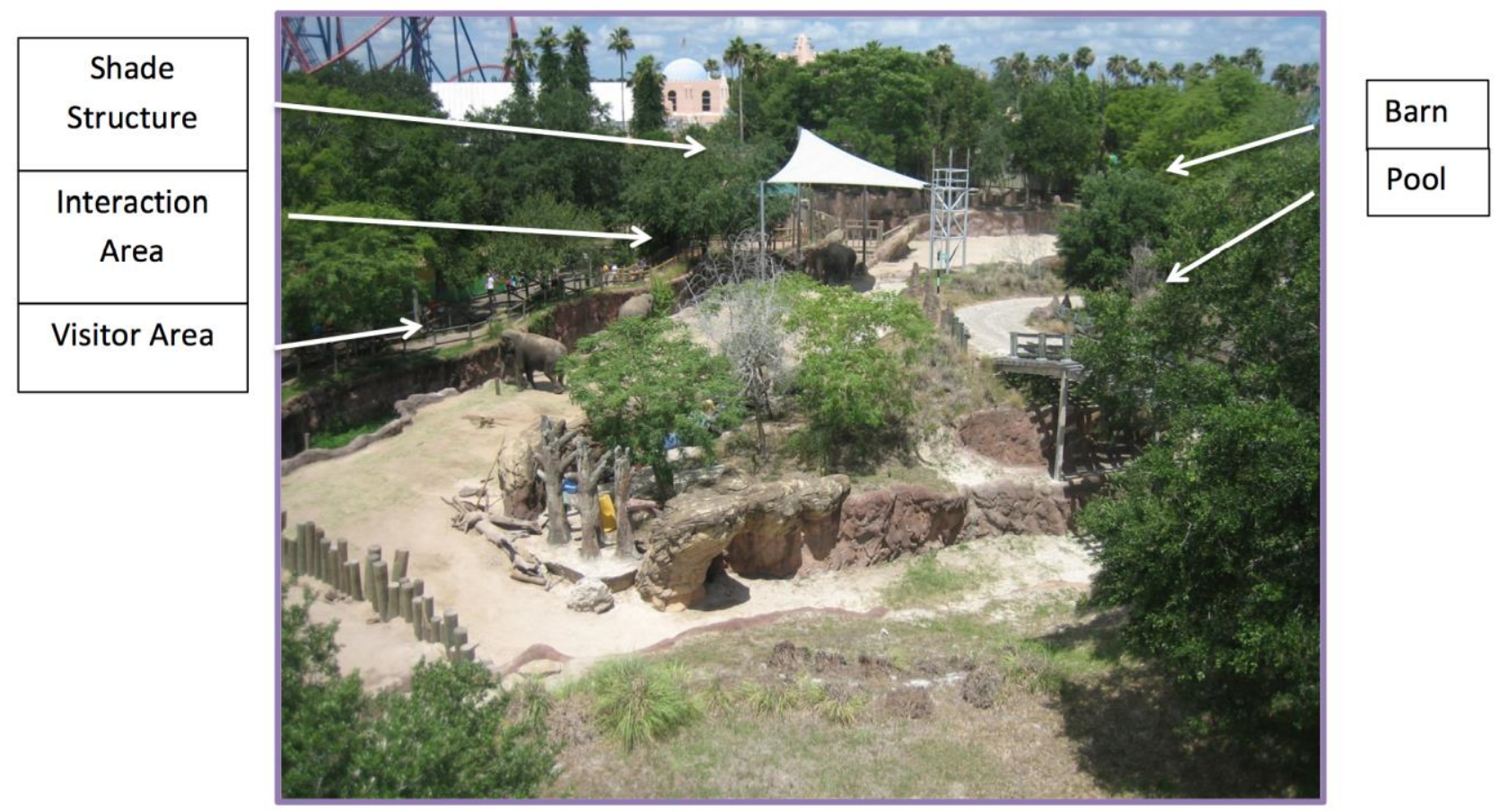

Figure 1. Image of elephant habitat. 


\section{Data Collection}

The elephants in this study were observed for two 24-hour (about 06:30 to 06:30 hr the next day), five $14 \mathrm{hr}$ (about 06:30 to 20:30 hr) and one $9 \mathrm{hr}(06: 30$ to 15:30 h) observation periods. The one $9 \mathrm{hr}$ observation period was shorter due to inclement weather that prevented observations from continuing for a full 14 hrs. Continuous observation of behavior (Martin \& Bateson, 1993) occurred for one or two focal animals per diurnal observation period and four to five focal animals per nocturnal observation period. Focal animals were picked randomly for each observation period. The number of focal animals was based on the number of observers available. Focal animals were randomly assigned to observers. A total of four University of Guelph graduate students, were involved as the only observers throughout the study. Each observer only recorded the behavior of one animal at a time. All observers underwent rigorous pre-study training that included a trial $4 \mathrm{hr}$ observation period. Observations occurred during May and June 2011. All time was recorded in Eastern Standard Time. Data were recorded by hand and later transferred to Microsoft Excel spreadsheets for analysis. In total, over 270 animal observation hours were analyzed.

Behavior was recorded during the day (between 06:30 to 20:30 hr) in 15 mutually exclusive categories (Table 2). In addition, six behavioral contexts were recorded (Table 3). Trainer interaction and hose play varies from other behaviors because the elephant trainers must be present to provide the opportunity to perform these behaviors, either by directly engaging the elephants or by turning on a hose for the elephants to use. Behavioral contexts were not recorded during trainer interaction because of the probability these were being influenced by the trainer's presence. Nocturnal observations included fewer behavioral categories and contexts because of the difficulty in clearly seeing some behaviors in the dark (Tables 4 and 5). An infrared camera was used to aid in nocturnal observations (ThermaCam SC 2000, FLIR Systems, Danderyd, Sweden). This current study is part of a larger investigation into Asian elephant behavior and thermoregulation.

Table 2

Ethogram Key of Mutually Exclusive Behaviors Recorded During Diurnal Observation Periods

\begin{tabular}{ll}
\multicolumn{1}{c}{ Behavior } & \multicolumn{1}{c}{ Description } \\
\hline Trainer interaction & Interaction with elephant trainers, solicited and spontaneous \\
Out of view & Behavior cannot be recorded because elephant is out of view \\
Standing & Standing with no forward or backward momentum \\
Walking & Movement of all four feet in forward or backward motion \\
Lying down & Lying down on the ground, side or prone \\
Eating & Using the trunk to pick up hay or concentrate and place it in the mouth; includes \\
& chewing; may include walking while chewing \\
Drinking & Manipulating water with the trunk and spraying it into the mouth \\
Enrichment & Interacting with any food item other than hay or concentrate and other non-food \\
& enrichment objects; may include walking \\
Spraying self & Manipulating water with trunk and spraying over any part of body \\
Spraying environment & Manipulating water with trunk and spraying it not on self \\
Hose playing & Interacting with water from any hose \\
Wading & Being immersed in water which does not touch the ventral area \\
Swimming & Being immersed in water which touches the ventral area \\
Urinating $^{\mathrm{b}}$ & Urination occurrence \\
Defecating & Defecation occurrence \\
\hline${ }^{\mathrm{a}}$ Eating and enrichment have been grouped together for ethogram analysis. \\
$\mathrm{b}^{\mathrm{b}}$ These behaviors have been grouped together as "Other" behavior for the ethogram analysis, due to their relatively low \\
frequency of occurrence.
\end{tabular}


Table 3

Ethogram Key of Behavioral Contexts Recorded During Diurnal Observation Periods

\begin{tabular}{ll}
\hline Context & Description \\
\hline Inside & Behavior recorded inside the elephant barn \\
Ear flapping & Moving ears rhythmically back and forth \\
Dust bathing & Collection of soil or hay and throwing it over the body \\
In shade - head & Having 50\% or more of the head in shade \\
In shade - body & Having 50\% or more of the body in shade \\
$\leq 1$ length to gunite & Being within one elephant length of any gunite wall
\end{tabular}

${ }^{a}$ Only behavioral context included in ethograms.

Table 4

Ethogram Key of Mutually Exclusive Behaviors Recorded During Nocturnal Observation Periods

\begin{tabular}{|c|c|}
\hline Behavior & Description \\
\hline Out of view & Behavior cannot be recorded because elephant is out of view \\
\hline Standing & Standing with no forward or backward momentum \\
\hline Lying down & Lying down on the ground, side or prone \\
\hline Eating ${ }^{\mathrm{a}}$ & $\begin{array}{l}\text { Using the trunk to pick up hay or concentrate and place it in the mouth; includes } \\
\text { chewing; may include walking while chewing }\end{array}$ \\
\hline Drinking ${ }^{\mathrm{b}}$ & Manipulating water with the trunk and spraying it into the mouth \\
\hline Enrichment $^{\mathrm{a}}$ & $\begin{array}{l}\text { Interacting with any food item other than hay or concentrate and other non-food } \\
\text { enrichment objects; may include walking }\end{array}$ \\
\hline Urinating ${ }^{\mathrm{b}}$ & Urination occurrence \\
\hline Defecation $^{\mathrm{b}}$ & Defecation occurrence \\
\hline \multicolumn{2}{|c|}{$\begin{array}{l}\text { a Eating and enrichment have been grouped together for ethogram analysis. } \\
\text { b These behaviors have been grouped together as "Other" behavior for the ethogram analysis, due to their relatively low } \\
\text { frequency of occurrence. }\end{array}$} \\
\hline \multicolumn{2}{|l|}{ Table 5} \\
\hline \multicolumn{2}{|c|}{ Ethogram Key of Behavioral Contexts Recorded During Nocturnal Observation Periods } \\
\hline Context & Description \\
\hline $\begin{array}{l}\text { Inside }{ }^{a} \\
\leq 1 \text { length to gunite }\end{array}$ & $\begin{array}{l}\text { Behavior recorded inside the elephant barn } \\
\text { Being within one elephant length of any gunite wall }\end{array}$ \\
\hline
\end{tabular}

${ }^{\mathrm{a}}$ Only behavioral context included in ethograms.

\section{Data Analysis}

Mutually exclusive behaviors were recorded continuously; the behavior performed for the majority of each minute was recorded. These behaviors were analyzed as percentage of observation period spent performing each behavior, to determine an activity time budget. Urination and defecation were analyzed as number of times these behaviors occurred during the observation period. Ethograms were created to analyze the pattern of behavior. Behavioral categories for the ethograms were condensed for simplicity and due to the low occurrence of certain behaviors (Tables 2-5).

\section{Results}

The diurnal activity time budgets of each elephant demonstrated considerable variation between elephants and between observation days (Table 6, Figure 2). The elephants spent 17-49\% of the daylight observation periods standing, $1-9 \%$ of the day walking, $19-44 \%$ of the day eating, and $1-20 \%$ of the day using enrichment items. Additionally, trainer interaction occurred for $4-23 \%$ of the day and drinking 
occurred for $1 \%$ or less of the day. Urination occurred 2-6 times and defecation occurred 1-7 times during the day.

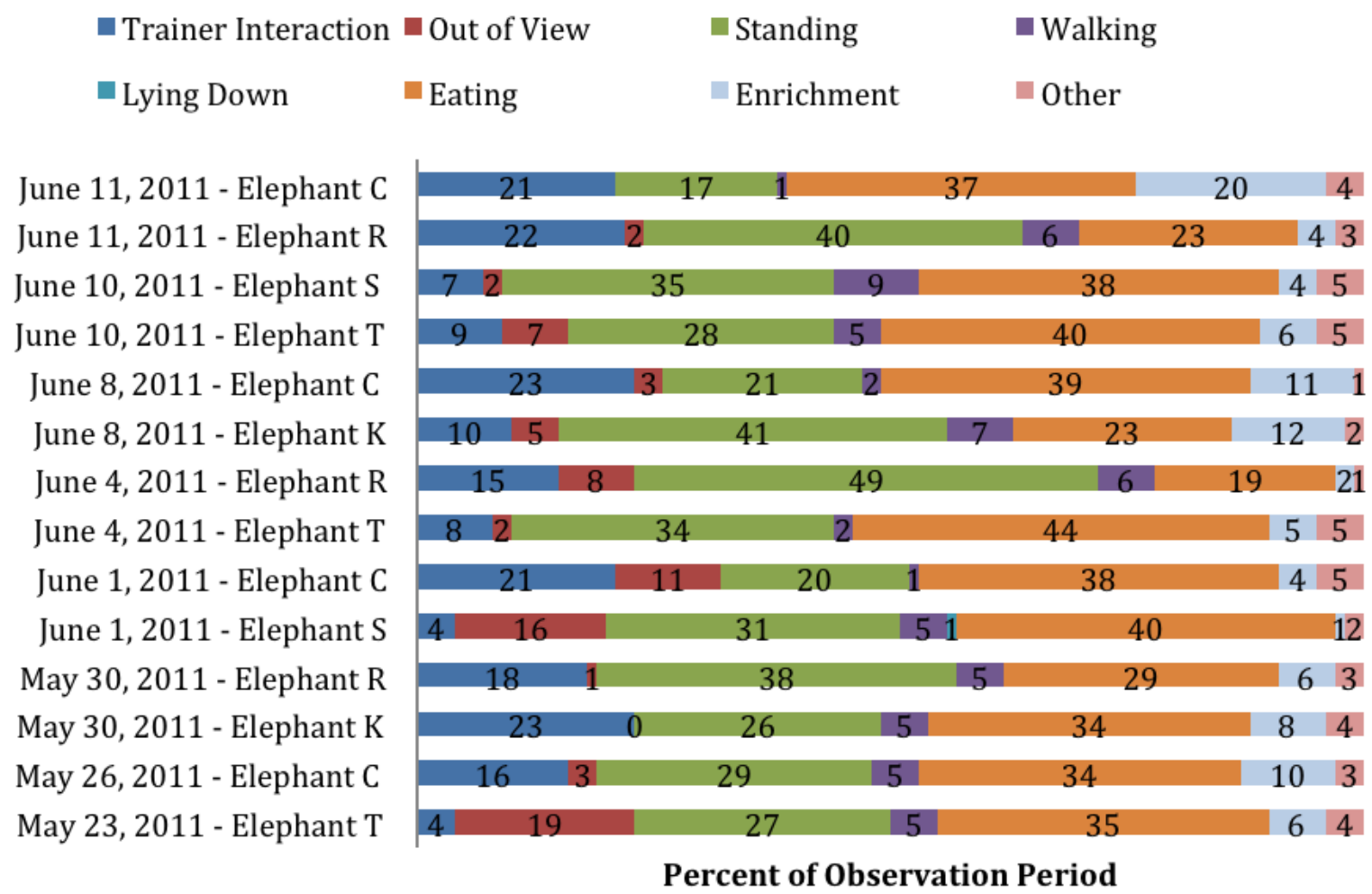

Figure 2. Diurnal activity time budgets for each elephant and observation period, shown as a stacked chart. All observation periods started at 6:30 and were $14 \mathrm{hrs}$ long, except for June $1^{\text {st }}$, which was $9 \mathrm{hrs}$ long. Sunrise and sunset times for these dates in 2011: June 11, 06:33 - 20:26 hr. June 10, 06:33 - 20:25 hr. June 8, 06:33 - 20:25 hr. June 4: 06:33 - 20:23 hr. June 1: 06:34 20:21 hr. May 30: 06:34 - 20:20 hr. May 26: 06:36 - 20:18 hr. May 23, 06:37 - 20:16 hr (United States Naval Observatory).

Diurnal behaviors could vary considerably between elephants. For example, on June 11th Elephant C spent $17 \%$ of the day standing, while Elephant R spent $40 \%$ of the day standing. On the same day, Elephant R spent $23 \%$ of the day eating and $4 \%$ of the day using enrichment items, while Elephant $\mathrm{C}$ spent $37 \%$ of the day eating and $20 \%$ of the day using enrichment items. Diurnal activity budgets also varied between observation days. For example, Elephant K spent $26 \%$ of the day standing and $34 \%$ of the day eating on May 30th, and $41 \%$ of the day standing and $23 \%$ of the day eating on June 8th.

Some behaviors were also highly variable at night, with differences between elephants and between observation nights (Table 7, Figure 3). At night, the elephants spent $29-87 \%$ of the observation period standing, $1-19 \%$ of the night eating, and $0.1-10 \%$ of the night using enrichment items. The elephants did not lie down during the day, except elephant $\mathrm{S}$ once inside the elephant barn. At night, elephants spent $0-45 \%$ of the observation period lying down. Lying down behavior varied greatly between elephants and nights. For example, Elephant $\mathrm{C}$ spent $13 \%$ of the first night and $45 \%$ of the second night lying down. Conversely, Elephant K spent $42 \%$ of the first night and $18 \%$ of the second night lying down. Drinking occurred for 0-1\% of the night; while urination occurred 0-3 times and defecation occurred at most once per night. 
Table 6

Range of Percentages of Diurnal Observation Period Spent in Each Mutually Exclusive Behaviour, for Each Elephant and the Group

\begin{tabular}{|c|c|c|c|c|c|c|c|c|c|c|c|c|c|c|c|}
\hline 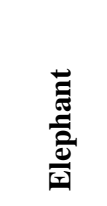 & 章 & 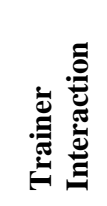 & 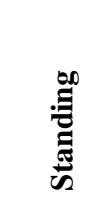 & 照 & 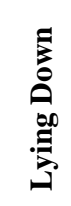 & 包 & 垃 & 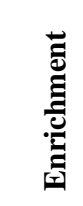 & 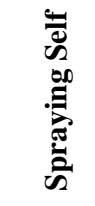 & 恶总 & 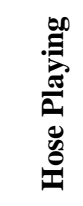 & 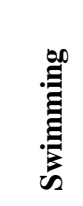 & 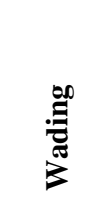 & مَّ & 苞 \\
\hline $\mathrm{T}$ & $2-19$ & $4-9$ & $27-34$ & $2-5$ & 0 & $35-44$ & 1 & $5-6$ & $<1-3$ & $0-1$ & $0-2$ & 0 & 0 & $3-4$ & $1-6$ \\
\hline $\mathrm{S}$ & $2-16$ & $4-7$ & $31-35$ & $5-9$ & $0-1$ & $38-40$ & 1 & $1-4$ & $<1$ & $0-<1$ & $1-3$ & 0 & $<1$ & 2 & $2-4$ \\
\hline $\mathrm{K}$ & $0-5$ & $10-23$ & $26-41$ & $5-7$ & 0 & $23-34$ & $<1$ & $8-12$ & $0-1$ & $0-<1$ & $<1$ & $0-1$ & 0 & $4-6$ & $2-7$ \\
\hline $\mathrm{R}$ & $1-8$ & $15-22$ & $38-49$ & $5-6$ & 0 & $19-29$ & $<1-1$ & $2-6$ & 0 & $0-<1$ & $0-1$ & $0-1$ & 0 & $3-4$ & $3-7$ \\
\hline $\mathrm{C}$ & $0-11$ & $16-23$ & $17-29$ & $1-5$ & 0 & 34-39 & $<1-1$ & $4-20$ & $0-1$ & $0-<1$ & $<1-1$ & 0 & 0 & $3-5$ & $2-4$ \\
\hline Group & $0-19$ & $4-23$ & $17-49$ & $1-9$ & $0-1$ & $19-44$ & $<1-1$ & $1-20$ & $0-3$ & $0-1$ & $0-3$ & $0-1$ & $0-<1$ & $2-6$ & $1-7$ \\
\hline
\end{tabular}

${ }^{a}$ Number of time behavior occurred during observation period.

Table 7

Range of Percentages of Nocturnal Observation Period Spent in Each Mutually Exclusive Behaviour, for Each Elephant and the Group

\begin{tabular}{|c|c|c|c|c|c|c|c|c|}
\hline Elephant & Out of View & Standing & Lying Down & Eating & Drinking & Enrichment & Urinating ${ }^{\mathbf{a}}$ & Defecating \\
\hline $\mathrm{T}$ & $30-54$ & $29-53$ & 1 & $6-14$ & $<1-1$ & $<1-10$ & $1-3$ & 0 \\
\hline S & 8 & 87 & 0 & 1 & 0 & 4 & 1 & 0 \\
\hline $\mathrm{K}$ & $6-10$ & $33-67$ & $18-42$ & $1-8$ & $<1-1$ & $6-8$ & $0-2$ & $0-1$ \\
\hline $\mathrm{R}$ & $1-8$ & $69-87$ & 0 & $3-19$ & $<1-1$ & $4-8$ & 2 & 1 \\
\hline $\mathrm{C}$ & $1-8$ & $43-67$ & $13-45$ & $4-5$ & $0-<1$ & $6-7$ & 3 & 0 \\
\hline Group & $1-54$ & $29-87$ & $0-45$ & $1-19$ & $0-1$ & $<1-10$ & $0-3$ & $0-1$ \\
\hline
\end{tabular}

${ }^{\mathrm{a}}$ Number of time behavior occurred during observation period. 
Out of View $\quad$ Standing $\quad$ Lying Down $\quad$ Eating $\quad$ Enrichment $\quad$ Other

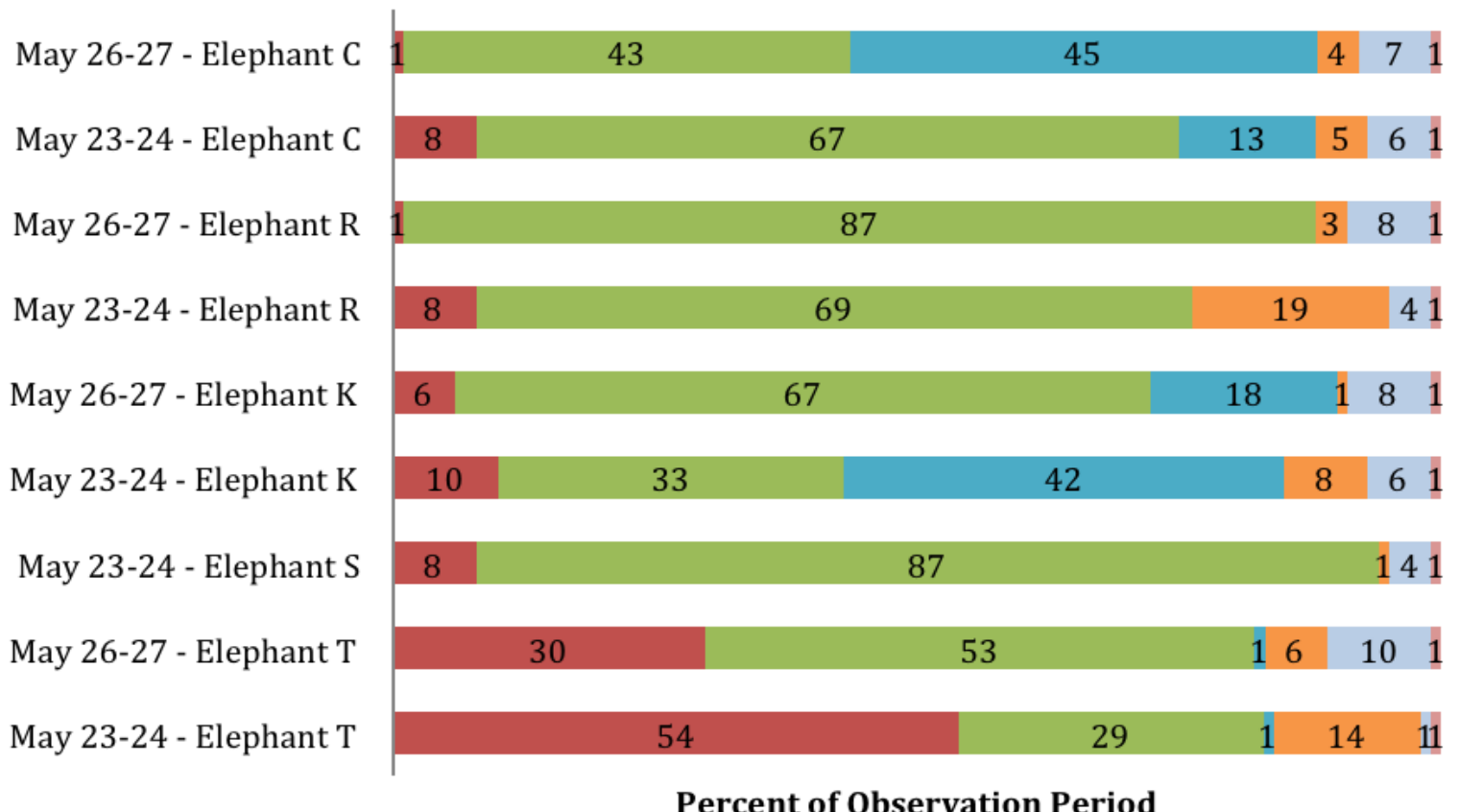

Figure 3. Nocturnal activity time budgets for each elephant and observation period, shown as a stacked chart. All observation periods were $10 \mathrm{hrs}$ long and started at 20:30. Sunset and sunrise times for these dates in 2011: May 26 - 27, 20:18 - 06:35 hr. May $23-24,20: 16-06: 36 \mathrm{hr}$.

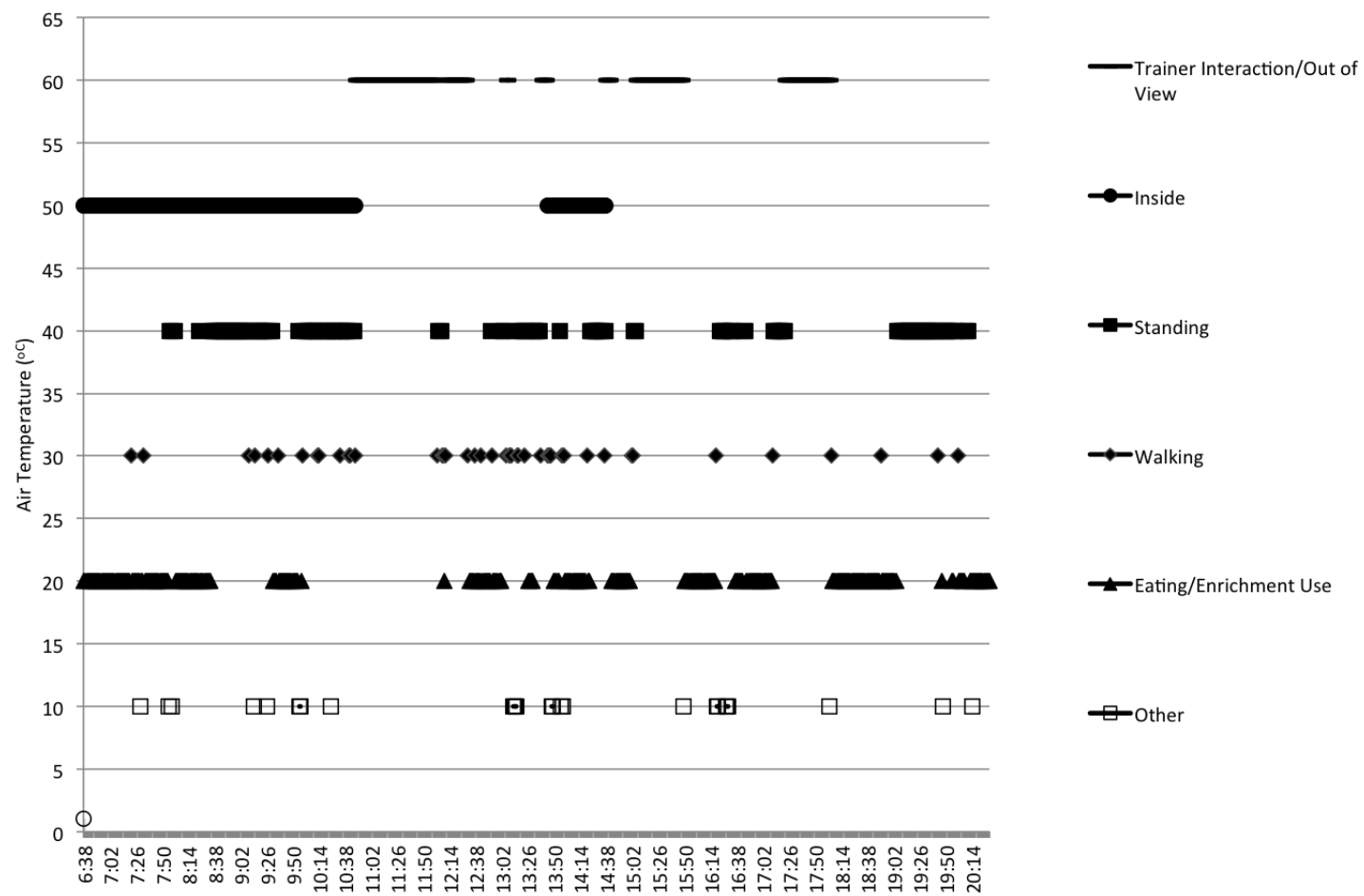

Figure 4. Sample diurnal ethogram, Elephant K on May 30, 2011. 

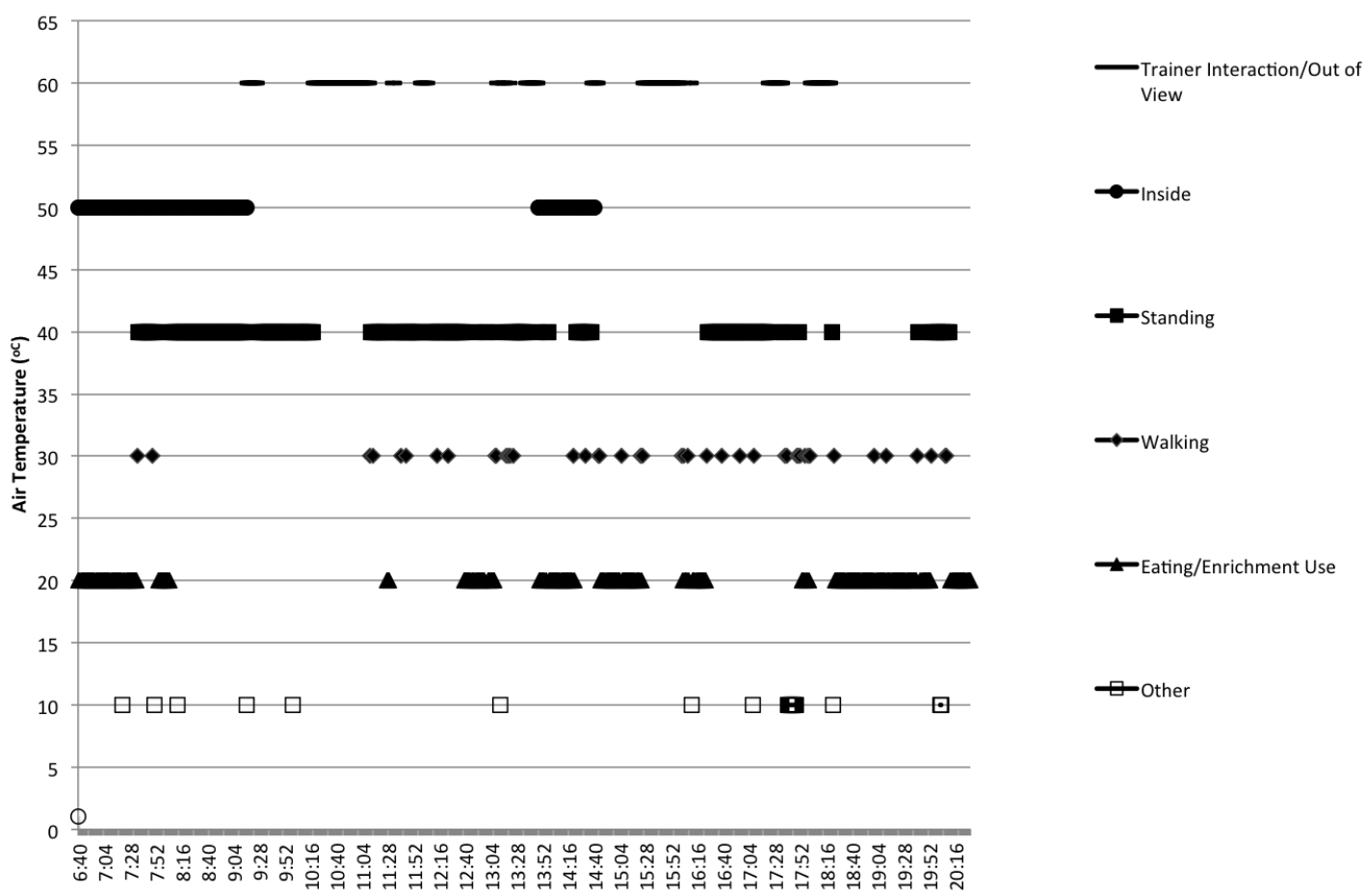

Figure 5. Sample diurnal ethogram, Elephant R, May 30, 2011.

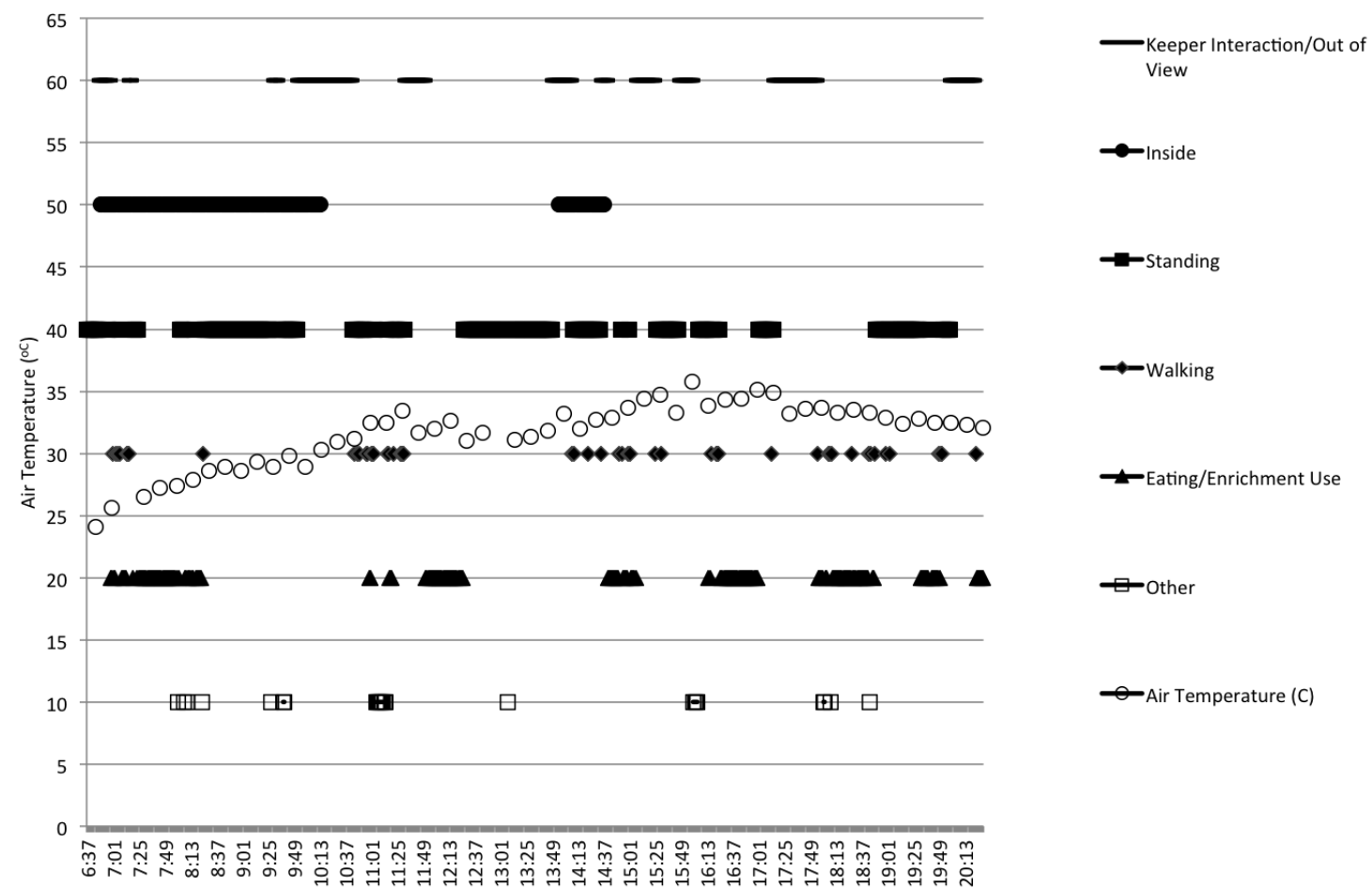

Figure 6. Sample diurnal ethogram, Elephant R, June 11, 2011. 
The sample diurnal ethograms (Figures 4-6) show activity patterns over the observation period. The ethograms were selected as a sample comparison between elephants (Elephant $\mathrm{K}$ and Elephant $\mathrm{R}$ on May 30th, Figures 4 and 5), and between observation days (Elephant R on May 30th and June 11th, Figures 5 and 6).

\section{Discussion}

\section{Eating Behavior}

The diurnal eating time seen in the current study (19-44\% of the observation period) is considerably lower than that which is seen in wild elephants. In wild elephants, about $16 \mathrm{hrs}$ of $24 \mathrm{hrs}$ will be spent foraging (McKay, 1973; Stoinsky et al., 2000). A large proportion of a wild elephant's diet is made up of low quality vegetation, with only $35-46 \%$ of the food actually digested (McKay, 1973; Roehrs et al., 1989; Shoshani \& Eisenberg, 1982). Therefore, a wild elephant needs to spend a large amount of time to locate and eat sufficient quantities of feed to meet nutritional requirements. This means $60-80 \%$ of waking hours are spent eating and 150 to $350 \mathrm{~kg}$ (wet weight) of feed is consumed per day (Dougall, 1964; Owen-Smith, 1988; Shoshani \& Eisenberg, 1982). One study found a wild foraging time of over $90 \%$ during the day and night when feed quality was especially low, due to seasonal and habitat differences (McKay, 1973).

The ready availability of feed in a zoological park setting may be the cause of a decreased amount of time spent eating compared to wild conspecifics. In the wild, acquiring feed, such as stripping leaves from a tree, is more time consuming than processing feed as it is normally presented in a captive setting (Veasey, 2006). Kurt and Schmid (1996) found adult Asian elephants at zoological parks consume $4.3 \mathrm{~kg}$ of feed (dry weight) per hour, while wild elephants consume only $2.3 \mathrm{~kg}$ of feed per hour, which may reflect both the availability and the quality of food in zoological parks, compared to the wild. The higher quality of feed, compared to a wild setting, also means a smaller volume of feed is adequate to meet nutritional requirements (Wiedenmayer, 1998).

The diurnal eating time seen in the current study (19-44\% of the day) is similar to other studies of captive elephants. Schmid, Heistermann, Glanslober, and Hodges (2001) studied six female elephants in European zoos and found $29-64 \%$ of observation hours (08:00 to 18:00 hr) were spent foraging and drinking. Rees (2009) observed $27-41 \%$ of the study time (10:00 to $14: 00 \mathrm{hr}$ ) was spent feeding by six adult Asian elephants in a zoological park (five cows and one bull).

While feed quality and availability may explain the lower amount of time spent eating by the group of elephants in the current study, compared to wild conspecifics, considerable variation exists between elephants and observation periods. For example, the elephant with the lowest body condition score and body weight (Elephant T) had the highest eating time (44\%) on June 4th, while Elephant R, the elephant with the highest body condition score and body weight, had the lowest eating time (19\% of the day) during the same observation period. On another observation day (May 30th), Elephant R spent more time eating (29\% of the day); however, Elephant $\mathrm{T}$ ate more than Elephant R on all observation days when their behavior was recorded. In terms of access to feed, Elephant $\mathrm{T}$ is the matriarch and the most dominant animal, which may increase access to resources (Freeman, Weiss, \& Brown, 2004). However, the elephants in this study appeared to have equal access to resources since feed was spread throughout the habitat, hay was given ad libitum, and treats, including fruits and grains, were distributed to all elephants throughout the day. Furthermore, differences in body weight, contradictory to amount of time spent eating, may be related to other factors, such as individual variations in digestion (Hatt \& Clauss, 2006).

While few nocturnal studies have been reported for Asian elephants to allow comparison, the nocturnal eating time seen in the current study (1-19\%) seems lower than expected, as the elephants had hay available throughout the night. Wild Asian and African elephants spend a similar time eating at night (60-80\% of the night) as during the day (McKay, 1973; Owen-Smith, 1988). Some Asian elephants in the wild have been seen to continuously feed during the night (Joshi \& Singh, 2008). In one study of a single 
captive female African elephant, less time was spent feeding at night (about $13 \%$ of the night when outside and about $32 \%$ of the night inside) than during the day (about $38 \%$ outside and $43 \%$ inside). Three female African elephants at Zoo Atlanta were found to feed for about $47 \%$ of the time, between 17:00 and 08:00 hr (Wilson et al., 2006), which is similar to previous studies by Brockett, Stoinski, Black, Markowitz, and Maple (1999) on the same group of elephants (41.91\% nocturnal feeding time in 1992 and $34.84 \%$ in 1994).

A number of possible explanations may explain the lower than expected nocturnal feeding time seen in this study. For example, the elephants in the current study may feed enough during the day to meet nutritional requirements, and require less feed at night, and thus eat less at night. Furthermore, the elephants may be more motivated to perform resting behaviors (standing or lying down) at night, due to the presence of trainers during the day. The elephants may also have been more motivated to eat when fresh feed is presented, with the last fresh feed being provided between 21:30 and 1:30.

\section{Walking Behavior}

Walking occurred for $1-9 \%$ of the diurnal observation periods. Time spent walking is difficult to compare to previous studies, as some studies include walking in the definition of eating when performed simultaneously (e.g., Rees, 2009), while others do not (e.g., Posta, 2011), and some have a certain distance or number of steps the animal must complete in the definition of locomotion (e.g., Wilson et al., 2006). Walking in the current study is defined as movement of all four feet in a forward or backward motion. The overall walking time may be underestimated, as the definition of eating and enrichment use includes walking if occurring simultaneously. Furthermore, trainer interaction may include walking as the trainers ask the elephants to move from one area of the habitat to another, as well as elephants following or soliciting attention from trainers. This may be the reason that the walking time seen in the current study is lower than that seen in other studies of captive Asian elephants (6.1-19.2\%; Rees, 2009) and captive African elephants (about 27\% during the day outside, Posta, 2011).

The amount of trainer interaction and eating time may be inversely related to walking time in the group of elephants in the current study. For example, Elephant C spent 1-2\% of the daytime observation period walking, when trainer interaction occurred for 21-23\% of the day, and eating took up 37-39\% of the day, whereas Elephant $\mathrm{C}$ walked $5 \%$ of the day when trainer interaction only occurred for $16 \%$ of the day and eating occurred for $34 \%$ of the day.

One other factor that may affect walking is the age of the elephant. Rees (2009) found age affected activity patterns, including locomotion, when comparing elephants from 1-43 years of age. In the current study, the oldest animal (Elephant S) had the highest amount of walking ( $9 \%$ of the day). However, all the elephants except Elephant $\mathrm{K}$ were similar in age (41-45 years; elephant $\mathrm{K}$ - 22 years), and thus age is not a variable than can be examined conclusively in this study.

\section{Enrichment Use}

The use of enrichment items also varied considerably between elephants and observation periods, from $1-20 \%$ of the day and $0.1-10 \%$ of the night. All elephants interacted with newly placed enrichment items when they first returned to the outdoor exhibit in the early afternoon (for examples, Figures 4-6). Since enrichment items given to the elephants were changed daily, and novel enrichment items are more likely to be stimulating for the animals (Kuczaj, Lacinak, Trone, Solangi, \& Ramos, 2002; Shyne, 2006), the elephants may be more motivated to use newly placed enrichment items when first returning to the outdoor exhibit. However, this does not explain why such variability in enrichment use was seen between elephants and between observation days. For example, Elephant $\mathrm{C}$ used enrichment items for $4 \%$ of the day on June 1st and for $20 \%$ of the day on June 11th, even though trainer interaction (21\% of the day) and eating time (38 and $37 \%$ of the day respectively) were similar. The elephants were not brought inside in the afternoon on June 1st, however enrichment items were still provided. Previous studies have seen mixed results when considering whether an increase in enrichment use is associated with a decrease in 
inactivity. Stoinski et al. (2000) did find a negative correlation between enrichment use and inactivity, while Gloyns (2000) did not find such a correlation.

A number of reasons may explain why enrichment use varied between elephants and observation days. Wild elephants have been seen to prefer certain plant species over others (Shoshani \& Eisenberg, 1982). As the produce and browse used as enrichment differed day to day, elephants may have been more motivated to use the enrichment items if a preferred fruit, vegetable or browse species was provided.

Dominance status may affect enrichment use in elephants. Dominance status has been shown to affect aggression and access to resources (Freeman et al., 2004). However, the most submissive animal, Elephant C, had the highest enrichment use seen in this study (20\% v range for other elephants). Since enrichment items are spread throughout the habitat and all elephants have access to these items, dominance status may not be a factor in this study. Individual differences in temperament may better account for differences in enrichment use. For example, differences in curiosity have been noted in elephants, based on keeper questionnaires (Freeman et al., 2004). Previous research has found different personality traits among the elephants in this study, in regards to interactions with their physical world (Highfill, Fad, Makecha, \& Kuczaj, 2013; Yasui et al., 2013). Furthermore, estrous state may affect enrichment use, as estrous state has been shown to influence aggression and investigative behavior (Slade-Cain, Rasmussen, Schulte, 2008). No data is available on the estrous state of the elephants during the current study.

\section{Trainer Interaction Behavior}

Trainer interactions included a variety of sessions involving the elephants and trainers, sometimes scheduled, but often spontaneous and sometimes initiated by the elephants. Interactions could be husbandry sessions for veterinary procedures, learning sessions for teaching new behaviors or reinforcing known behaviors, quiet relationship-building time involving tactile stimulation of the elephants, or less structured play-times. The training staff continuously monitored the elephants and determined scheduling and session-types on the basis of their collective assessment of the individual elephants' behavior and needs. Although elephants always had the option of terminating an interaction by leaving at any time, they rarely chose to do so. For this reason, we excluded trainer interactions from activity-budget analysis.

\section{Lying Down Behavior}

The elephants in the current study did not lie down during the day, except Elephant $\mathrm{S}$ who laid down for six minutes inside the barn once. Adult wild Asian and African elephants generally do not lie down during the day either (Owen-Smith, 1988). This is also consistent with studies of captive Asian and African elephants (Posta, 2011; Rees, 2009).

While the current study did not look at sleep behavior in particular because of the difficulty in determining when sleep occurs, the elephants in the current study varied greatly in their lying down behavior at night. Elephant T laid down for $1 \%$ of both nights (3-6 min). Elephant S did not lie down the first night of observation, and was not observed the second night. Elephant K laid down $42 \%$ of the first night $(240 \mathrm{~min}$ ) and $18 \%$ of the second night (107 min). Elephant R spent $0 \%$ of both nights lying down. Elephant $\mathrm{C}$ spent $13 \%$ of the first night lying down $(73 \mathrm{~min})$, which is similar to the average recumbent sleep time of 72 min seen by Tobler (1992). Elephant C's lying down time was greater on the second night at $45 \%$ of the observation period (268 min). Tobler (1992) looked at sleep in captive zoo and circus elephants, including total sleep (recumbent and standing sleep) which was 4 to 6.5 hrs. However, nearly all of the elephants studied by Tobler (1992) were chained at night, which may have caused differences in their behavior compared to unchained conspecifics (Gruber et al., 2000). The elephants in the current study are not chained.

Brockett et al. (1999) also found less variation in lying down time than in the current study. The African elephants in their study spent about 32\% of the night (4.8 hrs) lying down in 1992 and about 33\% 
of the night (4.6 hrs) lying down in 1994. In the wild, during the night, sleep has been reported to occur for 1 to 3 hrs in Asian elephants (Owen-Smith, 1988).

Except Elephant $\mathrm{S}$, all elephants in this group laid down outside, at night, during previous studies (Laforest, Finegan, Miller, Fad, \& Atkinson, 2011). In this study, Elephant R was not seen lying down. It should be noted that lying down behavior may have occurred when elephants were out of sight. Furthermore, while the elephants did not appear to be influenced by the presence of observers outside the habitat, they are not used to having observers at night.

\section{Drinking, Urination, and Defecation}

In the wild, Asian elephants may drink one or more times per day, with drinking usually occurring in early evening (Owen-Smith, 1988). In the current study, drinking occurred for less than 1-1\% of the day and $0-1 \%$ of the night, with varying numbers of bouts per day and night.

Wild Asian elephants will defecate 12-18 times a day during the wet season, and less during the dry season (Owen-Smith, 1988; Vancuylenberg, 1977). In the current study, the elephants defecated one to seven times during the day and once or never at night. The decreased frequency of defecation may be related to the quality of feed, as zoo elephants generally receive a higher quality of feed than found in the wild (Hatt \& Clauss, 2006). Therefore, less quantity and more highly digestible feed may equate to decreased frequency of defecation in captivity.

Urination occurred two to six times during the day and zero to three times at night. This is consistent with previous studies on the current group of elephants (Laforest et al., 2011), and similar to a study by Benedict and Lee (1936) that reported urination on average 5 times per day and 5 to 6 times per night. Urination in African elephants has been reported to occur more often (Schotsman, Atkinson, Finegan, \& Miller, 2008).

\section{Conclusion}

1. Considerable variation was found in activity time budgets between elephants and observation days, for both diurnal and nocturnal observation periods.

2. Previous studies of captive and wild elephants have also reported variation in activity time budgets between studies and between individual elephants.

3. Eating time was considerably shorter in this study than that seen in wild elephants, although similar to other captive elephant studies.

4. Results of this study will allow further comparison between groups of elephants and will help to inform management strategies.

\section{Acknowledgements}

The authors wish to thank the staff at Busch Gardens Tampa, without whom this study would not have been possible. The Pachyderm Palace team of Diane Donahue, Melissa Gramling, Kari Hosford, Erin Ivory, Tara Jimenez, Nancy Kaufman, Vicki Perrington, Chrissy Pratt and Katie Stutz provided valuable insight and assisted greatly in data collection. Thank you to Allison Van Slack and Julia Molnar for helping with data collection. Thank you also to Dr. Terry Gillespie for lending us the meteorological equipment, and to Yuri Montanholi for his help with the thermal imaging camera. Finally, we wish to thank Dr. Judy St Leger for her support of this research.

\section{References}

Benedict, F. G., \& Lee, R. C. (1936). Studies on the body temperature of elephants. Proceedings of the National Academy of Sciences, 22, 405-408. 
Brockett, R. C., Stoinski, T. S., Black, J., Markowitz, T., \& Maple, T. L. (1999). Nocturnal behavior in a group of unchained female African elephants. Zoo Biology, 18, 101-109.

Choudhury, A. U. (1999). Status and conservation of the Asian elephant Elephas maximus in north eastern India. Mammal Review, 29, 141-173.

Choudhury, A., Lahiri Choudhury, D. K., Desai, A., Duckworth, J. W., Easa, P. S., Johnsingh, A. J. T., ...Wikramanake, E. (2008). Elephas maximus. The IUCN Red List of Threatened Species 2008, e.T7140A12828813. http://dx.doi.org/10.2305/IUCN.UK.2008.RLTS.T7140A12828813.en.

Clubb, R., \& Mason, G. (2002). A review of the welfare of zoo elephants in Europe: A report commissioned by the RSPCA. Oxford, UK: University of Oxford.

Dougall, H. W. (1964). The chemical composition of a day's diet of an elephant. East African Wildlife Journal, 2, 51-59.

Fernando, P., Wickramanayake, E., Weerakoon, D., Jayasinghe, L. K. A., Gunawardene, M., \& Janaka, H. K. (2005). Perceptions and patterns in human elephant conflict in old and new settlements in Sri Lanka: Insights for mitigation and management. Biodiversity Conservation, 14, 2465-2481.

Freeman, E. W., Weiss, E., \& Brown, J. L. (2004). Examination of the interrelationships of behavior, dominance status, and ovarian activity in captive Asian and African elephants. Zoo Biology, 23, 431-448.

Gloyns, R. (2000, July). Long-term enrichment for captive elephants. Proceedings of the 2nd Annual Symposium on Zoo Research, 2000, 69-71.

Gruber, T. M., Friend, T. H., Gardner, J. M., Packard, J. M., Beaver, B., \& Bushong, D. (2000). Variation in stereotypic behavior related to restraint in circus elephants. Zoo Biology, 19, 209-221.

Hatt, J. M., \& Clauss, M. (2006). Feeding Asian and African elephants. International Zoo Yearbook, 40, $88-95$.

Highfill, L., Fad, O., Makecha, R., \& Kuczaj, S. (2013). Asian elephants (Elephas maximus) may demonstrate stable personalities. International Journal of Comparative Psychology, 26, 223-240.

Horback, K. M., Miller, L. J., Andrews, J. R. M., \& Kuczaj, S. A. (2014). Diurnal and nocturnal activity budgets of zoo elephants in an outdoor facility. Zoo Biology, 33, 1-8.

Joshi, R., \& Singh, R. (2008). Feeding behavior of wild Asian elephants (Elephas maximus) in the Rajaji National Park. American Scientist Online, 4, 34-48.

Koehl, D. (2001). Captive elephant database. Elefant-Consult. Retrieved from www.elephant.se/main.htm. Downloaded on 01 November 2015.

Kuczaj, S., Lacinak, T., Trone, M., Solangi, M., \& Ramos, J. (2002). Keeping environmental enrichment enriching. International Journal of Comparative Psychology, 15, 127-137.

Kurt, F., \& Schmid, J. A. (1996, September). A comparison of feeding behavior and body weight in Asian elephants (Elephas maximus). Paper presented at the First International Symposium on Physiology and Ethology of Wild and Zoo Animals, Berlin, Germany.

Laforest, B. J., Finegan, E. J., Miller, S. P., Fad, O.C., \& Atkinson, J. L. (2011). Thermoregulation in the Asian elephant (Elephas maximus). Proceedings of the American Zoo and Aquarium Association Annual Conference.

Martin, P., \& Bateson, P. (1993). Measuring behavior: An introductory guide (2nd ed.). Cambridge, UK: Cambridge University Press.

McKay, G. M. (1973). Behavior and ecology of the Asiatic elephant in southeastern Ceylon. Smithsonian Contributions to Zoology, 125, 1-113.

Owen-Smith, R. N. (1988). Megaherbivores: The influence of very large body size on ecology. Cambridge, UK: Cambridge University Press.

Posta, B. (2011). The effect of housing and enrichment on zoo elephant behavior. (unpublished Master's thesis). Bowling Green State University: Bowling Green, $\mathrm{OH}$.

Rees, P. A. (2009). Activity budgets and the relationship between feeding and stereotypic behaviors in Asian elephants (Elephas maximus) in a zoo. Zoo Biology, 28, 79-97.

Roehrs, J. M., Brockway, C. R., Ross, D. V., Reichard, T. A., \& Ullrey, D. E. (1989). Digestibility of Timothy hay by African elephants. Zoo Biology, 8, 331-337.

Schmid, J., Heistermann, M., Glanslober, U., \& Hodges, J. K. (2001). Introduction of foreign female Asian elephants (Elephas maximus) into an existing group: Behavioral reactions and changes in cortisol levels. Animal Welfare, 10, 357-372.

Schotsman, M. J., Atkinson, J. L., Finegan, E. J., \& Miller, S. P. (2008). Thermoregulation by the African elephant, Loxodonta africana. Elephant Managers Association Conference, Orlando, FL. 
Shoshani, J., \& Eisenberg, J. F. 1(982). Elephas maximus. Mammalian Species, 182, 1-8.

Shyne, A. (2006). Meta-analytic review of the effects of enrichment on stereotypic behavior in zoo mammals. Zoo Biology, 25, 317-337.

Slade-Cain, B. E., Rasmussen, L. E. L., \& Schulte, B. A. (2008). Estrous state influences on investigative, aggressive, and tail flicking behavior in captive female Asian elephants. Zoo Biology, 27, 167-180.

Stoinski, T. S., Daniel, E., \& Maple, T. L. (2000). A preliminary study of the behavioral effects of feeding enrichment on African elephants. Zoo Biology, 19, 485-493.

Sukumar, R. (1992). The Asian elephant: Ecology and management (2nd ed.). Cambridge, UK: Cambridge University Press.

Tobler, I. (1992). Behavioral sleep in the Asian elephant in captivity. Sleep, 15, 1-12.

Tresz, H., \& Wright, H. (2006). Let them be elephants! How Phoenix Zoo integrated three "problem" animals. International Zoo News, 53, 154-160.

United States Naval Observatory. Retrieved from www.usno.navy.mil/data/docs/RS_OneYear.php. Downloaded on 24 January 2016.

Vancuylenberg, B. W. B. (1977). Feeding behavior of the Asiatic elephant in south-east Sri Lanka in relation to conservation. Biological Conservation, 12, 33-54.

Veasey, J. (2006). Concepts in the care and welfare of captive elephants. International Zoo Yearbook, 40, 63-79.

Wiedenmayer, C. (1998). Food hiding and enrichment in captive Asian elephants. Applied Animal Behaviour Science, 56, 77-82.

Wilson, M. L., Bashaw, M. J., Fountain, K., Kieschnick, S., \& Maple, T. L. (2006). Noctural behavior in a group of female African elephants. Zoo Biology, 25, 173-186.

Wilson, M. L., Bloomsmith, M. A., \& Maple, T. L. (2004). Stereotypic swaying and serum cortisol concentrations in three captive African elephants (Loxodonta africana). Animal Welfare, 13, 39-43.

Yasui, S., Konno, A., Tanaka, M., Idani, G., Ludwig, A., Lieckfeldt, D., \& Inoue-Murayama, M. (2013). Personality assessment and its association with genetic factors in captive Asian and African elephants. Zoo Biology, 32, 70-78. 